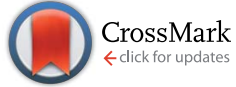

Cite this: RSC Adv., 2016, 6, 68835

Received 19th May 2016

Accepted 11th July 2016

DOI: $10.1039 / c 6 r a 13085 b$

www.rsc.org/advances

\section{Shedding light on the soft and efficient free radical induced reduction of graphene oxide: hidden mechanisms and energetics $\dagger$}

\begin{abstract}
A. Kahnt, ${ }^{\star a}$ R. Flyunt, ${ }^{\text {b }}$ S. Naumov, ${ }^{\text {b }}$ W. Knolle, ${ }^{b}$ S. Eigler, ${ }^{\text {cd }}$ R. Hermann ${ }^{\text {e }}$ and B. Abel ${ }^{\star b e}$
Reduction of graphene oxide (GO) in aqueous dispersions by strongly reducing free radicals has recently been identified to be a very powerful approach, because functional groups are removed softly but efficiently, and non-volatile impurities as well as defects are largely avoided. However, the reaction mechanisms remained somewhat speculative. Recently we showed that $\mathrm{GO}$ can be efficiently reduced in water by indirect photoreduction mediated by $\left(\mathrm{CH}_{3}\right)_{2} \cdot \mathrm{C}(\mathrm{OH})$ radicals generated via the reaction of triplet acetone with isopropanol. Those radicals efficiently defunctionalize oxo-groups of GO forming the carbon lattice without generating additional defects. In this comprehensive study we shed more light on the reaction mechanism of reduction of $\mathrm{GO}$ by $\mathrm{H}^{*}, \mathrm{CO}_{2} \cdot{ }^{\cdot-},\left(\mathrm{CH}_{3}\right)_{2} \cdot \mathrm{C}(\mathrm{OH})$ and $\mathrm{CH}_{3} \mathrm{C} \cdot \mathrm{H}(\mathrm{OH})$ by combining pulsed radiolysis and determine its overall energetics via quantum-chemical calculations. In timedependent experiments mechanistic insights have been obtained and unknown intermediates have been discovered. Moreover, different reduction mechanisms, such as radical addition, electron-transfer, concerted water elimination and $\mathrm{HCO}_{3}{ }^{-}$elimination are identified. Here we show that all mechanisms lead to $\mathrm{sp}^{2}$-carbon formation and therefore high quality graphene by reductive defunctionalization.
\end{abstract}

\section{Introduction}

Graphene is a highly promising material for a large number of future applications, such as its use in molecular electronic devices, ${ }^{1-5}$ sensors, ${ }^{6,7}$ as well as light harvesting, ${ }^{\mathbf{8}, 9}$ or energy storage devices, ${ }^{\mathbf{8 1 0 , 1 1}}$ and many more applications are still to come soon. Several approaches for the efficient production of graphene were suggested. These methods, however, all come with a number of problems and practical issues. Especially the production of high quality monolayer graphene with the perspective of large scale applications is still challenging. ${ }^{\mathbf{1 2 , 1 3}}$ One alternative is the use of graphene oxide (GO), which can be easily delaminated into monolayers and subsequently

${ }^{a}$ Department of Chemistry and Pharmacy, Chair of Physical Chemistry I, Friedrich-Alexander-Universität Erlangen-Nürnberg, Egerlandstrasse 3, 91058 Erlangen, Germany. E-mail: axel.kahnt@fau.de

${ }^{b}$ Leibniz Institute of Surface Modification (IOM), Chemical Department, Permoserstr. 15, 04303 Leipzig, Germany.E-mail: bernd.abel@iom-leipzig.de

'Department of Chemistry and Pharmacy, Institute of Advanced Materials and Processes (ZMP), Friedrich-Alexander-Universität Erlangen-Nürnberg (FAU), Henkestr. 42, 91054 Erlangen, Germany

${ }^{d}$ Department of Chemistry and Chemical Engineering/Organic Chemistry, Chalmers University of Technology, 41296 Göteborg, Sweden

${ }^{e}$ Wilhelm-Ostwald-Institute for Physical and Theoretical Chemistry, Universität Leipzig, Linne-Strasse 2, 04103 Leipzig, Germany

$\dagger$ Electronic supplementary information (ESI) available: UV/vis spectra upon electron beam radiolysis, pulse radiolysis spectra and time absorption profiles. See DOI: 10.1039/c6ra13085b reduced. ${ }^{13-15}$ A large number of methods for reducing GO into graphene-like materials employing chemical reduction methods, such as reduction with $\mathrm{N}_{2} \mathrm{H}_{4}, \mathrm{HI} /$ trifluoroacetic acid, or ascorbic acid were published. ${ }^{\mathbf{1 3 , 1 4 , 1 6}}$ However, beyond their merits nearly all of the approaches have also serious drawbacks; they are either raising technical concerns with regard to their up-scalability (e.g. using $\mathrm{N}_{2} \mathrm{H}_{4}$ ), they do not produce high quality rGO or they are not environmentally friendly due to by-products, which are of environmental concern.

The reduction of GO using reducing free radicals formed by radiation chemical or photochemical approaches attracted attention in the last few years. Among all methods of free radical generation radiation chemistry provides the best choice to generate radicals of defined structure in a wide range of solvents and temperatures. Recent studies ${ }^{17-21}$ provided solid evidence for the feasibility of the reduction of GO in aqueous dispersion using radiation- or photochemical methods.

Recently, we highlighted the large benefits and softness of free radical reduction of GO. In this study different GO samples were efficiently reduced with photochemically generated $\left(\mathrm{CH}_{3}\right)_{2} \mathrm{C}^{*}(\mathrm{OH})^{22}$ The obtained rGO from this approach showed conductivity values up to $5500 \mathrm{~S} \mathrm{~m}^{-1}$, which indicates the efficiency of the method. Moreover, it is extremely simple to realize and up-scale the reduction method. ${ }^{22}$ Unfortunately, the mechanism and kinetic details of the reduction processes remained elusive. Information on molecular mechanisms, kinetics, and energetics are needed, however, to understand why the GO reduction employing free radicals leads to high- 
quality rGO, containing only a very small amount of residual functional groups, ${ }^{17,22}$ as well as for any serious up-scaling attempts. Considering up-scaling as a longer term perspective, precise knowledge of mechanisms and rate constants is required for drawing mass and heat balances as well as selecting the right photo reactor type etc. In spite of their apparent importance it is surprising that detailed mechanistic studies for the relevant chemical reduction reactions are only rarely spotted in the literature, ${ }^{23}$ such as a recent study focusing on the reduction of GO by solvated electrons $\left(\mathrm{e}_{\mathrm{aq}}{ }^{-}\right)$in water. ${ }^{21}$

In the light of the latter we selected four reductive free radicals with a vide rage of reduction potentials (2.3-1.2 $\mathrm{V}$ vs. NHE) namely $\mathrm{H}^{\cdot}, \mathrm{CO}_{2}{ }^{--},\left(\mathrm{CH}_{3}\right)_{2} \mathrm{C}^{\cdot}(\mathrm{OH})$, and $\mathrm{CH}_{3} \mathrm{C}^{*} \mathrm{H}(\mathrm{OH})$. All of them known in the literature for their general feasibility to reduce GO efficiently. ${ }^{17-23}$ All selected reducing radicals are easy and exclusively accessible in aqueous GO dispersions using pulse radiolysis, which allows for monitoring the reactions of the radicals with GO spectroscopically and kinetically. This in mind, we performed a combined spectroscopic and kinetic study based on pulse radiolysis complemented by quantum chemical calculations. The latter is giving insights into the energetics of the investigated reactions. Moreover the quantum chemical studies allow to investigate multistep reactions of GO, in which the GO flake reacts after the initial reaction with a reducing free radical with further reducing free radicals. This is helpful since the concentration of free radicals formed by pulse radiolysis is much lower than the GO concentration, hampering the time resolved observation of these further reaction steps.

\section{Experimental section}

\section{Materials}

All chemicals were purchased from commercial sources in highest purity and used as received. Three different GO samples have been investigated in this work: (I) single-layered GO purchased from Cheaptubes.com (Cambridgeport, VT, USA) - further called CT-GO, (II) GO from Nanoinnova Technologies (Madrid, Spain) further called NI-GO, and (III) oxo-functionalized graphene (oxo$\mathbf{G}_{1}$ ), which exhibits an average density of defects of only $0.3 \%$ within the carbon skeleton ${ }^{\mathbf{1 3}}$ synthesized according to ref. 24 . Dispersions of GO were prepared in a Millipore water using bath ultrasonication, for details see ref. 17.

\section{Pulse radiolysis}

The samples were saturated with either $\mathrm{H}_{2}, \mathrm{~N}_{2}$ or $\mathrm{N}_{2} \mathrm{O}$ and irradiated with high energy electron pulses $(1 \mathrm{MeV}, 15 \mathrm{~ns}$ duration) by a pulse transformer type electron accelerator (Elit Institute of Nuclear Physics, Novosibirsk, Russia). The dose delivered per pulse was measured by electron dosimetry. ${ }^{25}$ Electron pulses with a dose of 100, 50 and 20 Gy were selected. The optical detection of the transients was carried out with a detection system consisting of a pulsed (pulser MSP 05 Müller Elektronik Optik) xenon lamp (XBO 450, Osram), a SpectraPro 500 monochromator (Acton Research Corporation), a R9220 photomultiplier (Hamamatsu Photonics), and a $500 \mathrm{MHz}$ digitizing oscilloscope (TDS 640, Tektronix). ${ }^{26}$
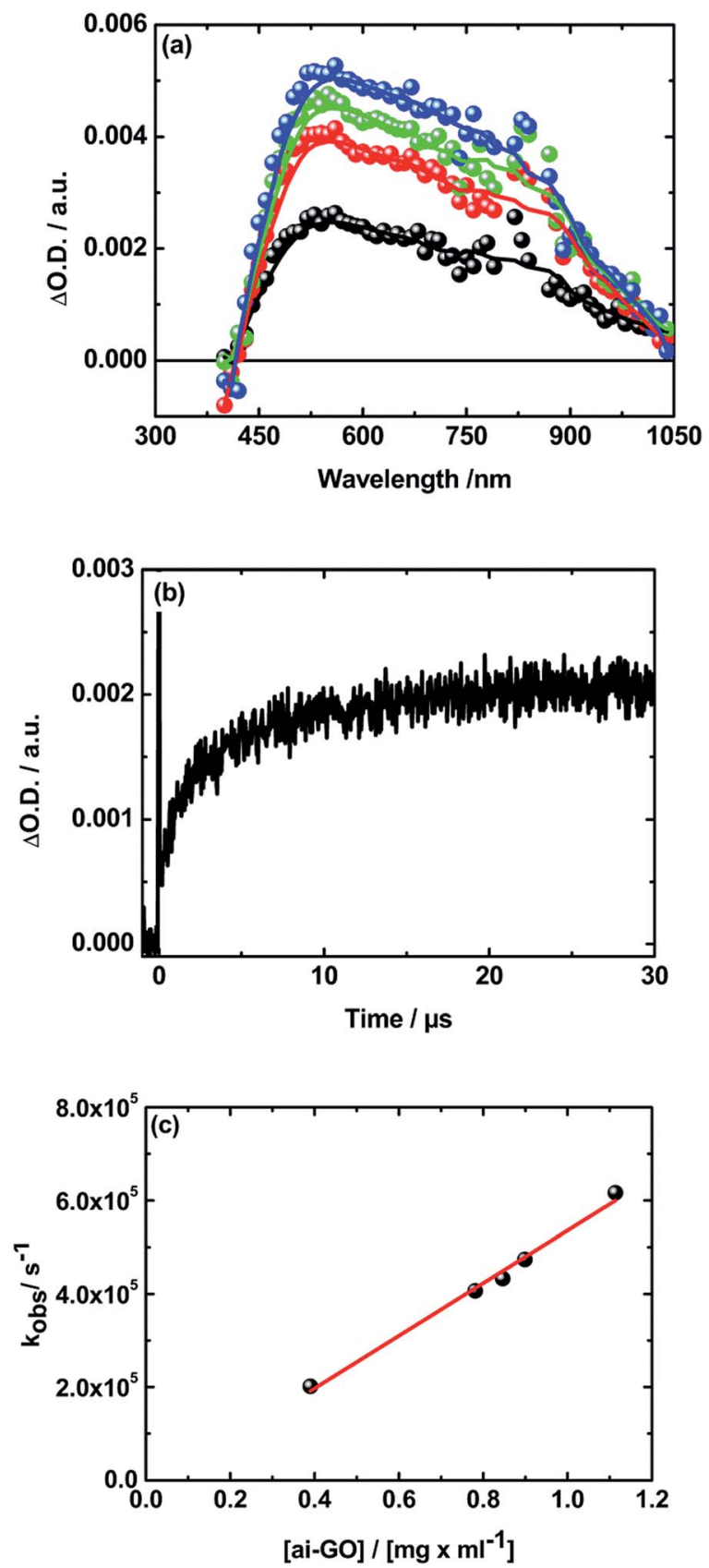

Fig. 1 (a) Differential absorption spectra obtained upon electron pulse radiolysis (100 Gy, 15 ns FWHM) of $0.78 \mathrm{mg} \mathrm{ml}^{-1}$ oxo- $\mathrm{G}_{1}$ in $\mathrm{H}_{2}$-saturated aqueous solution containing $\mathrm{HClO}_{4}(\mathrm{pH} 3)$ with time delays of 1.5 $\mu \mathrm{s}$ (black), $5 \mu \mathrm{s}$ (red), $10 \mu \mathrm{s}$ (green) and $25 \mu \mathrm{s}$ (blue) after the electron pulse. (b) Corresponding absorption time profile at $520 \mathrm{~nm}$. (c) Plot of the pseudo-first-order rate constants taken from the $520 \mathrm{~nm}$ absorption time profiles vs. the oxo- $\mathrm{G}_{1}$ concentration.

\section{Electron-beam radiolysis}

The preparative irradiations of the GO systems were performed with $10 \mathrm{MeV}$ linear electron accelerators: ELEKTRONIKA (Toriy, Moscow, Russia) and MB10-30MP (Mevex, Stittsville, Canada). UV-vis spectra were measured with a TIDAS-II (Spectralytics GmbH, Essingen, Germany) UV-VIS spectrometer. 
Table 1 Rate constants for the reactions between the three different $\mathrm{GO}$ samples and $\mathrm{e}_{\mathrm{aq}}{ }^{-}, \mathrm{H}^{\cdot}, \mathrm{CO}_{2}{ }^{-},\left(\mathrm{CH}_{3}\right)_{2}{ }^{\circ} \mathrm{C}(\mathrm{OH})$ and $\mathrm{CH}{ }_{3} \mathrm{C} \cdot \mathrm{H}_{(\mathrm{OH})}$

\begin{tabular}{|c|c|c|c|c|}
\hline Reducing species & $\begin{array}{l}\text { Reduction potential of the } \\
\text { reducing transient } v s . \mathrm{NHE}^{a}\end{array}$ & $\begin{array}{l}\text { Oxo-G } \\
k_{2} / \mathrm{ml} \mathrm{mg}^{-1} \mathrm{~s}^{-1}\end{array}$ & $\begin{array}{l}\text { CT-GO } \\
k_{2} / \mathrm{ml} \mathrm{mg}^{-1} \mathrm{~s}^{-1}\end{array}$ & $\begin{array}{l}\text { NI-GO } \\
k_{2} / \mathrm{ml} \mathrm{mg}^{-1} \mathrm{~s}^{-1}\end{array}$ \\
\hline $\mathrm{e}_{\mathrm{aq}}{ }^{-}$ & $-2.8 \mathrm{~V}$ & $2.8 \times 10^{7 b}$ & $1.2 \times 10^{7 b}$ & $2.3 \times 10^{7 b}$ \\
\hline $\mathrm{CO}_{2}^{\cdot-}$ & $-2.0 \mathrm{~V}$ & $2.5 \times 10^{4}$ & $4.5 \times 10^{4}$ & $5.0 \times 10^{4}$ \\
\hline$\left(\mathrm{CH}_{3}\right)_{2} \mathrm{C}^{*}(\mathrm{OH})$ & $-1.4 \mathrm{~V}$ & $5.2 \times 10^{4}$ & $1.2 \times 10^{5}$ & $8.1 \times 10^{4}$ \\
\hline $\mathrm{CH}_{3} \mathrm{C}^{*} \mathrm{H}(\mathrm{OH})$ & $-1.2 \mathrm{~V}$ & $7.7 \times 10^{4}$ & ND & ND \\
\hline
\end{tabular}

${ }^{a}$ Values taken from ref. $34 .{ }^{b}$ Values taken from ref. $21 .{ }^{c}$ Value taken from ref. $33 .{ }^{d}$ ND - not determined.

\section{Quantum chemical calculations}

By means of quantum chemical method, the energetics of reactivity of model GO with the hexagonal $6 \times 5$ graphene sheet and two $\mathrm{OH}$ groups with various radicals (given in Fig. 5-8) was studied using Density Functional Theory (DFT) B3LYP method $^{27,28}$ as implemented in the Jaguar program version 8.3. ${ }^{29}$ The structures were optimized in water at B3LYP/6-31(d) level of theory. To take solvent effect (water) on the structure and reaction parameters of studied molecules into account, the calculations were done using Jaguar's dielectric continuum Poisson-Boltzmann solver (PBF),$^{30}$ which fits the field produced by the solvent dielectric continuum to another set of point charges. It was shown that the $6-31 \mathrm{G}$ basis set is sufficient to describe the major features of the electronic character of these compounds. ${ }^{31}$ The frequency analysis was made at the same level of theory to obtain thermodynamic parameters such as total enthalpy $(H)$ and Gibbs free energy $(G)$ at $298 \mathrm{~K}$. The reaction enthalpies $(\Delta H)$ and Gibbs free energies of reaction $(\Delta G)$ were calculated as the difference of the calculated total enthalpies $H$ and Gibbs free energies $(G)$ between the reactants and products respectively. It should be noted, that the most stable structure of used hexagonal $6 \times 5$ graphene sheet was calculated as triplet state. This is in agreement with the available literature data, ${ }^{31,32}$ that all DFT, semi-empirical, and HF methods with the exception of the B2PLYP density functional, predict the ground state triplet. Furthermore, the energetically favourable electronic structure of the used in this study model $\mathrm{GO}$ with two $\mathrm{OH}$ groups was calculated as triplet too.

\section{Results and discussion}

\section{Pulse radiolysis}

Radiolysis of water leads to the formation of three highly reactive species, namely $\mathrm{H}^{\circ},{ }^{\circ} \mathrm{OH}$ and $\mathrm{e}_{\mathrm{aq}}{ }^{-}$(eqn (1)) $\%$ besides molecular products such as $\mathrm{H}_{2} \mathrm{O}_{2}$ and $\mathrm{H}_{2}$. The radiation chemical yields of the primary species amount to $0.6 \times$ $10^{-7} \mathrm{~mol} \mathrm{~J}^{-1}$ for $\mathrm{H}^{\cdot}$ and $2.9 \times 10^{-7} \mathrm{~mol} \mathrm{~J}^{-1}$ for $\mathrm{e}_{\mathrm{aq}}{ }^{-}$and ${ }^{\cdot} \mathrm{OH}$.

\$ The $G$-value, i.e., the yield per absorbed energy is $0.6 \times 10^{-7} \mathrm{~mol} \mathrm{~J}^{-1}$ for $\mathrm{H}^{*}$ and $2.9 \times 10^{-7} \mathrm{~mol} \mathrm{~J}^{-1}$ for $\mathrm{e}_{\mathrm{aq}}{ }^{-}$and ${ }^{\circ} \mathrm{OH}$ which under our conditions results that the concentration of the reactive transients is much lower than the GO concentration making a pseudo-first order approximation feasible. This assumption is further corroborated by the fact that the observed kinetics was independent from the aborted dose and a linear relation between the GO concentration and the pseudo-first order rate constant was observed.
Hydrated electrons and hydrogen atoms are the most powerful reductants $\left(-2.8\right.$ and $-2.3 \mathrm{~V}$ vs. NHE, respectively) ${ }^{33,34}$ The reaction of hydrated electrons with GO was recently reported by us. ${ }^{21}$ In order to study the reactions of $\mathrm{H}$ atoms in water, two other intermediates, $\mathrm{e}_{\mathrm{aq}}{ }^{-}$and ${ }^{\circ} \mathrm{OH}$, have to be converted either directly to hydrogen atoms or to species of low reactivity which are not disturbing the pulse radiolysis measurements. This can be perfectly fulfilled by radiolysis of $\mathrm{H}_{2}$-saturated diluted solutions containing $1 \times 10^{-3} \mathrm{M} \mathrm{HClO}_{4}$, where a quantitative conversion of ${ }^{\circ} \mathrm{OH}$ and $\mathrm{e}_{\mathrm{aq}}{ }^{-}$into $\mathrm{H}^{\prime}$ is achieved via the reactions with hydrogen and protons (see eqn (2) and (3), respectively): ${ }^{35}$

$$
\begin{aligned}
& \mathrm{H}_{2} \mathrm{O} \longrightarrow \mathrm{H}^{\cdot}+{ }^{\circ} \mathrm{OH}+\mathrm{e}_{\mathrm{aq}}{ }^{-}(1) \\
& \mathrm{OH}+\mathrm{H}_{2} \rightarrow \mathrm{H}_{2} \mathrm{O}+\mathrm{H}^{\cdot} \\
& \mathrm{e}_{\mathrm{aq}}{ }^{-}+\mathrm{H}^{+} \rightarrow \mathrm{H}^{\cdot}
\end{aligned}
$$

The advantage of this approach instead utilizing the solvated electrons from the water radiolysis, is the higher yield of $\mathrm{H}$ atoms (the corresponding radiation-chemical yields are equal to $6.4 \times 10^{-7} \mathrm{~mol} \mathrm{~J}^{-1}$ and $3.5 \times 10^{-7} \mathrm{~mol} \mathrm{~J}^{-1}$, respectively). $\S$

Immediately after the electron pulse the transient spectra of the products of the water radiolysis are observed, but they are promptly converted into $\mathrm{H}^{*}$. Hydrogen atoms show an absorption deep in the UV region of the optical spectrum..$^{35}$ However, it can be hardly observed in solutions containing substantial amount of GO which shows strong absorption in the UV region.

The reaction of $\mathrm{H}^{*}$ with $\mathbf{0 x o}-\mathbf{G}_{\mathbf{1}}$ is showing the formation of a broad transient absorption in the range between $400 \mathrm{~nm}$ and $1050 \mathrm{~nm}$ with a maximum around $520 \mathrm{~nm}$ (Fig. 1a). This transient absorption is stable over the detection range of our experimental setup (up to $1 \mathrm{~ms}$ ). The plot of the pseudo-firstorder rate constants derived from the mono-exponential rise of the transient absorption around $520 \mathrm{~nm} v s$. $\mathbf{o x o}^{-\mathrm{G}_{\mathbf{1}}}$ concentration shows a linear relation resulting in a second-order rate constant of $k_{2}=5.6 \times 10^{6} \mathrm{ml} \mathrm{mg}^{-1} \mathrm{~s}^{-1}$.

$\S G\left(\mathrm{H}^{\cdot}\right)_{\text {overall }} \approx G\left({ }^{\circ} \mathrm{OH}\right)+G\left(\mathrm{e}_{\mathrm{aq}}{ }^{-}\right)+G\left({ }^{\circ} \mathrm{H}\right)_{\text {from water radiolysis }}$ with $G\left({ }^{\cdot} \mathrm{OH}\right)=2.9 \times 10^{-7}$ $\mathrm{mol} \mathrm{J}^{-1}, G\left(\mathrm{e}_{\mathrm{aq}}{ }^{-}\right)=2.9 \times 10^{-7} \mathrm{~mol} \mathrm{~J}^{-1}$, and $G\left(\mathrm{H}^{*}\right)_{\text {from water radiolysis }}=0.6 \times 10^{-7} \mathrm{~mol}$ $\mathrm{J}^{-1}$ under the assumptions that the solvated electrons are qualitatively converted into $\mathrm{H}^{*}$ by $\mathrm{H}^{+}$as well as ${ }^{\circ} \mathrm{OH}$ react with $\mathrm{H}_{2}$ exclusively to $\mathrm{H}^{*}$. Under the chosen conditions, these assumptions are reasonable. When $2 \mathrm{mM} t-\mathrm{BuOH}$ is added ${ }^{\circ} \mathrm{OH}$ is quenched efficiently and $G\left(\mathrm{H}^{*}\right)_{\text {overall }} \approx G\left(\mathrm{e}_{\mathrm{aq}}{ }^{-}\right)+G\left({ }^{\circ} \mathrm{H}\right)$. 

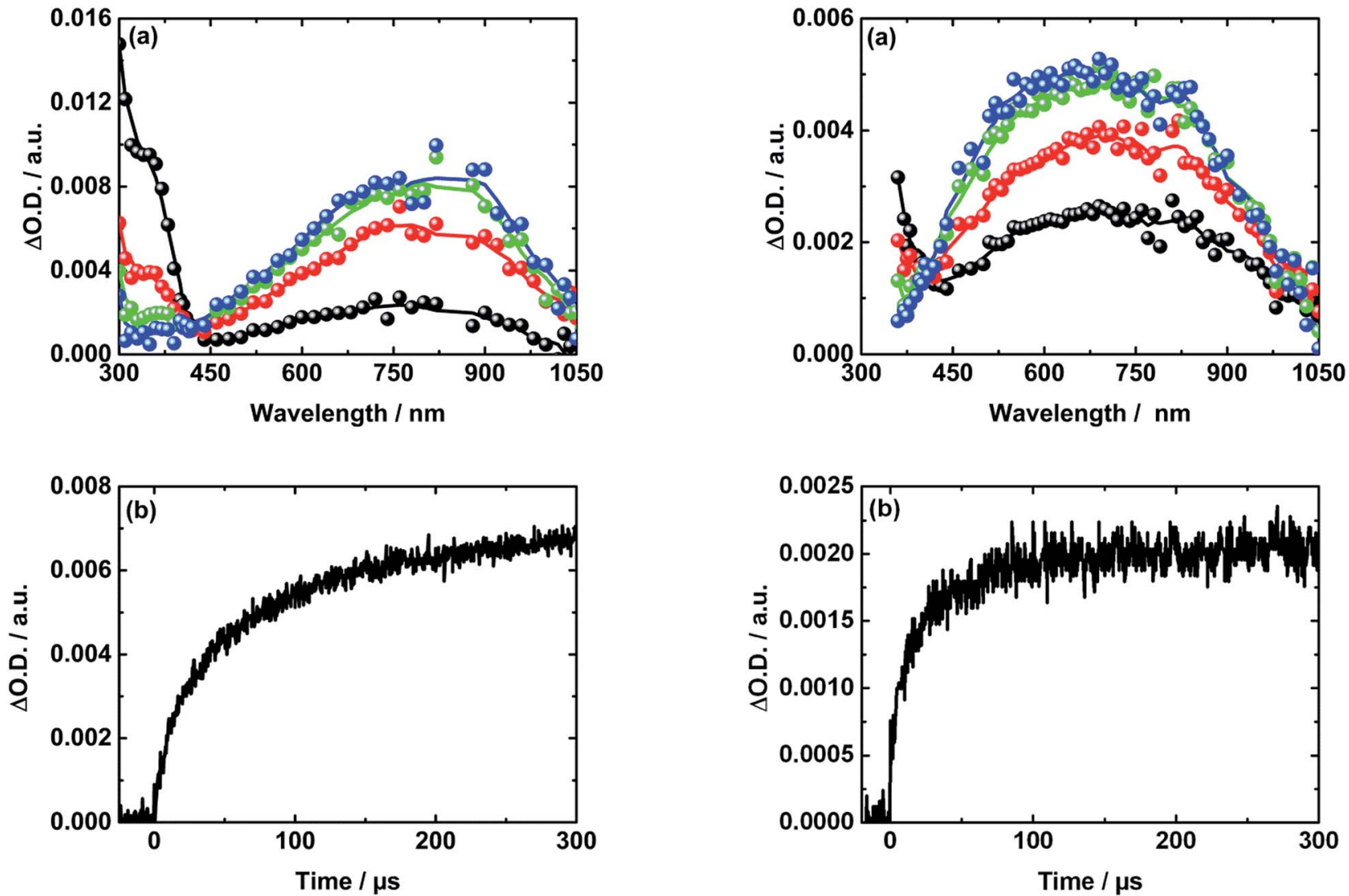

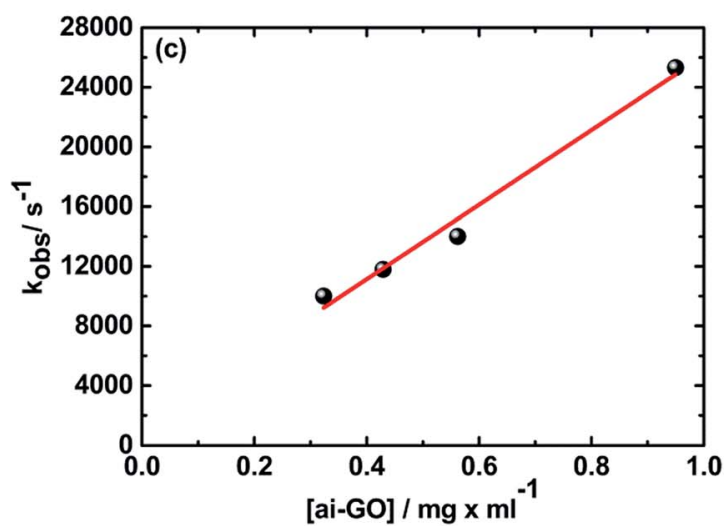

Fig. 2 (a) Differential absorption spectra received upon electron pulse radiolysis (100 Gy, 15 ns $\mathrm{FWHM}$ ) of $0.32 \mathrm{mg} \mathrm{ml}^{-1}$ oxo- $\mathrm{G}_{1}$ in $\mathrm{N}_{2} \mathrm{O}$ saturated aqueous solution in containing of $5 \times 10^{-3} \mathrm{M} \mathrm{HC(O)ONa}$ with time delays of $5 \mu \mathrm{s}$ (black), $50 \mu \mathrm{s}$ (red), $150 \mu \mathrm{s}$ (green) and $300 \mu \mathrm{s}$ (blue) after the electron pulse. (b) Corresponding absorption time profile at $700 \mathrm{~nm}$. (c) Plot of the pseudo-first-order rate constants taken from the $700 \mathrm{~nm}$ absorption time profiles vs. the oxo- $\mathrm{G}_{1}$ concentration.

Please note: GO is a label for a number of different heterogeneous materials (with very different defect numbers and features, i.e., functional groups), for which no classical solution concentration of the reactant in terms of $\mathrm{mol} \mathrm{l}^{-1}$ can be given. Instead we give rate constants (in $\mathrm{ml} \mathrm{mg}^{-1} \mathrm{~s}^{-1}$ ) as a function of the dispersed GO amount in solution $\left(\mathrm{mg} \mathrm{ml} \mathrm{ml}^{-1}\right)$. For the

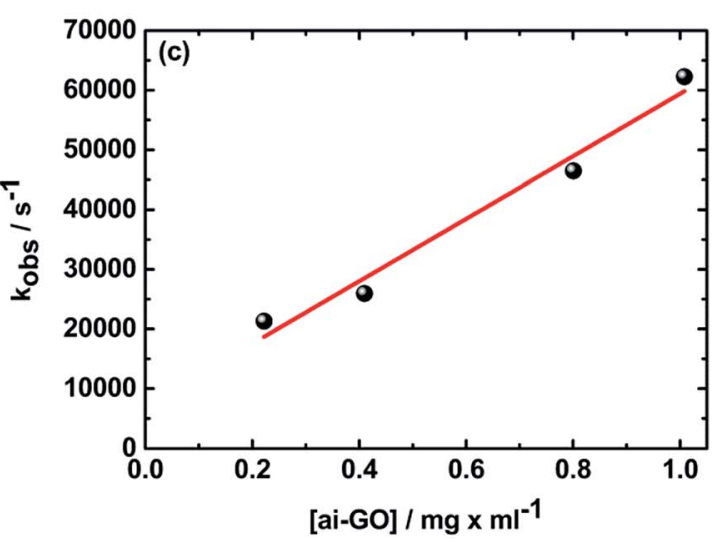

Fig. 3 (a) Differential absorption spectra obtained upon electron pulse radiolysis (100 Gy, 15 ns FWHM) of $0.22 \mathrm{mg} \mathrm{ml}^{-1}$ oxo- $\mathrm{G}_{1}$ in $\mathrm{N}_{2} \mathrm{O}$ saturated aqueous solution in the presence of 5 vol\% 2-propanol with time delays of $5 \mu \mathrm{s}$ (black), $25 \mu \mathrm{s}$ (red), $100 \mu \mathrm{s}$ (green) and $300 \mu \mathrm{s}$ (blue) after the electron pulse. (b) Corresponding absorption time profile at $700 \mathrm{~nm}$. (c) Plot of the pseudo-first-order rate constants taken from the $700 \mathrm{~nm}$ absorption time profiles vs. the oxo- $\mathrm{G}_{1}$ concentration.

compilation of the determined rate constants of the reaction of GO with reducing free radicals see Table 1.

Since the rate constant for the reaction of ${ }^{\circ} \mathrm{OH}$ with $\mathrm{H}_{2}$ is only $3.9 \times 10^{7} \mathrm{M}^{-1} \mathrm{~s}^{-1}, 36$ a reference experiment, adding a small amount $(2 \mathrm{mM})$ of tert-butanol $(t-\mathrm{BuOH})$ was performed. This amount of $t$ - $\mathrm{BuOH}$ is capable scavenging efficiently ${ }^{\circ} \mathrm{OH}$ since the rate constant for the reaction of $t-\mathrm{BuOH}$ with ${ }^{\circ} \mathrm{OH}$ is $\sim 6 \times$ 
$10^{8} \mathrm{M}^{-1} \mathrm{~s}^{-1}$ and with $\mathrm{H}^{*}$ is $\sim 1 \times 10^{5} \mathrm{M}^{-1} \mathrm{~s}^{-1} \cdot{ }^{37}$ Therefore, at these conditions the ${ }^{\circ} \mathrm{OH}$ radicals will not interfere reactions on the $\mu$ s time scale. On the other hand, the selected $t$-BuOH concentration is too small to interfere with the reaction between $\mathrm{H}^{*}$ and GO, since the reaction between $t$-BuOH and $\mathrm{H}^{*}$ would occur on the ms timescale. In a second reference experiment, the reaction of $\mathrm{GO}$, with ${ }^{\circ} \mathrm{OH}$ was probed and lead to a transient absorption maximizing at $560 \mathrm{~nm}$ (Fig. S1 in the ESI $\dagger$ ). The outcome of these reference experiments is providing solid evidences that the transient absorption with the maximum around $520 \mathrm{~nm}$ results from the reaction of $\mathrm{H}^{\circ}$ with $\mathrm{GO}$ and is not related to the reaction of GO with ${ }^{\circ} \mathrm{OH}$.

Noteworthy is the fact, that this transient absorption obtained by the reduction of GO with $\mathrm{H}^{*}$ is not matching with the absorption of reduced graphene oxide (rGO). The latter is the only end product of the GO reduction by reducing free radicals independently from their nature. The reduction of GO in aqueous solution is characterized by an overall increase of the absorption with a maximum around $260 \mathrm{~nm}$ (see Fig. S2 $\uparrow$ as an example). ${ }^{17-22}$ Therefore, the most feasible rational would be, that the reduction occurs in a multi-step mechanism and the observed transient absorption (Fig. 1a) shows intermediate of the GO reaction. In line with our theoretical studies three different mechanisms for the reaction of $\mathrm{H}^{*}$ with $\mathrm{GO}$ are considered. They are (i) a concerted reaction of $\mathrm{H}^{*}$ with $\mathrm{GO}$ forming directly $\mathrm{GO}^{\circ}$ and $\mathrm{H}_{2} \mathrm{O}$ (eqn (4)), (ii) a radical addition of the $\mathrm{H}^{\cdot}$ onto the GO basal plane (eqn (5)) and (iii) an electron transfer from $\mathrm{H}^{*}$ to $\mathrm{GO}$ resulting in $\mathrm{GO}^{--}$and $\mathrm{H}^{+}$(eqn (6)).

$$
\begin{gathered}
\mathrm{H}^{\bullet}+\mathrm{GO} \rightarrow \mathrm{GO}^{\bullet}+\mathrm{H}_{2} \mathrm{O} \\
\mathrm{H}^{\bullet}+\mathrm{GO} \rightarrow{ }^{\cdot} \mathrm{GO}-\mathrm{H} \\
\mathrm{H}^{\bullet}+\mathrm{GO} \rightarrow \mathrm{GO}^{--}+\mathrm{H}^{+}
\end{gathered}
$$

As shown by our theoretical calculations (see section Quantum chemical calculations, Fig. 5) all three proposed reaction pathways are energetically feasible and leading in follow up reactions to rGO.

Taking the feasibility of all three reaction pathways into account the rate constant of the reaction of $\mathrm{GO}$ with $\mathrm{H}^{*}$ should be considered as the overall rate constant for the reactions (46).

Another very powerful reductant, namely $\mathrm{CO}_{2}{ }^{--}(-2.0 \mathrm{~V} v s$. $\mathrm{NHE})^{34}$ was generated via reactions (7) and (8) in $\mathrm{N}_{2} \mathrm{O}$-saturated, aqueous solutions containing $5 \times 10^{-3} \mathrm{M} \mathrm{HC(O)ONa}$. Under such conditions the solvated electrons from the water radiolysis (eqn (1)) are quantitatively scavenged by $\mathrm{N}_{2} \mathrm{O}$ and transformed into ${ }^{\circ} \mathrm{OH}\left(\right.$ eqn (7)). The $\mathrm{H}^{\cdot}$ and ${ }^{\circ} \mathrm{OH}$ radicals react with $\mathrm{HC}(\mathrm{O}) \mathrm{O}^{-}$ under hydrogen abstraction affording $\mathrm{CO}_{2}{ }^{--}$(eqn (8))..$^{38}$

$$
\begin{gathered}
\mathrm{e}_{\mathrm{aq}}{ }^{-}+\mathrm{H}_{2} \mathrm{O}+\mathrm{N}_{2} \mathrm{O} \rightarrow{ }^{\cdot} \mathrm{OH}+\mathrm{OH}^{-}+\mathrm{N}_{2} \\
\cdot \mathrm{OH}\left(\mathrm{H}^{\cdot}\right)+\mathrm{HC}(\mathrm{O}) \mathrm{O}^{-} \rightarrow \mathrm{H}_{2} \mathrm{O}\left(\mathrm{H}_{2}\right)+\mathrm{CO}_{2}{ }^{-}
\end{gathered}
$$

The transient absorption obtained directly after the electron pulse shows the initial products of the water radiolysis, promptly converted into $\mathrm{CO}_{2}{ }^{\cdot-}$ with its characteristic transient absorption in the UV region of the optical spectrum. ${ }^{38}$ The reaction of $\mathrm{CO}_{2}{ }^{--}$with $\mathrm{GO}$ results in the decay of the transient absorption of $\mathrm{CO}_{2}{ }^{--}$accompanied by the rise of a new broad transient absorption band in the visible and NIR region of the optical spectrum with an isosbestic point around $400 \mathrm{~nm}$, clearly indicating that the formation of the new transient absorption relates to the reaction of GO with $\mathrm{CO}_{2}{ }^{-}$. This new
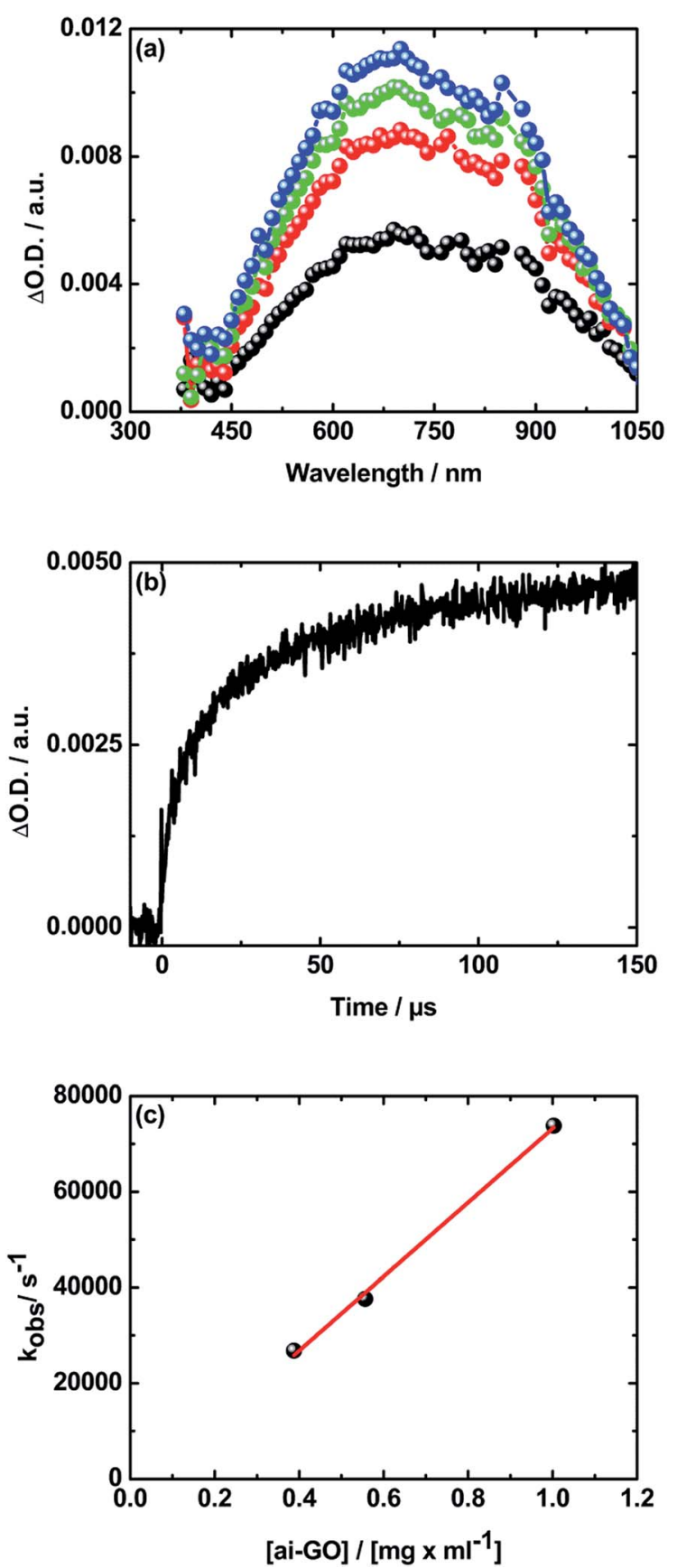

Fig. 4 (a) Differential absorption spectra received upon electron pulse radiolysis (100 Gy, $15 \mathrm{~ns}$ FWHM) of $0.39 \mathrm{mg} \mathrm{ml}^{-1}$ oxo- $\mathrm{G}_{1}$ in $\mathrm{N}_{2} \mathrm{O}$ saturated aqueous solution in the presence of 5 vol\% ethanol with time delays of $5 \mu \mathrm{s}$ (black), $25 \mu \mathrm{s}$ (red), $50 \mu \mathrm{s}$ (green) and $100 \mu \mathrm{s}$ (blue) after the electron pulse. (b) Corresponding absorption time profiles at 670 $\mathrm{nm}$. (c) Plot of the pseudo-first-order rate constants taken from the $700 \mathrm{~nm}$ absorption time profiles vs. the oxo- $\mathrm{G}_{1}$ concentration. 
transient absorption appears on the microsecond time scale and the pseudo-first-order rate constants obtained from the mono-exponential fitting of the rise at $800 \mathrm{~nm}$ are linearly dependent on the GO concentration. From the slope of this dependence the second-order rate constants of $2.5 \times$ $10^{4} \mathrm{ml} \mathrm{mg}^{-1} \mathrm{~s}^{-1}$ (oxo-G $), 4.5 \times 10^{4} \mathrm{ml} \mathrm{mg}^{-1} \mathrm{~s}^{-1}$ (CT-GO) and $5.0 \times 10^{4} \mathrm{ml} \mathrm{mg}^{-1} \mathrm{~s}^{-1}$ (NI-GO) were derived (see Fig. 2 for oxo$\mathbf{G}_{\mathbf{1}}$ and $\mathrm{S} 3$ and $\mathrm{S} 4 \uparrow$ for CT-GO and NI-GO, respectively).

As already described for the reaction of GO with ${ }^{\circ} \mathrm{H}$, the transient absorption formed by the reaction of GO with $\mathrm{CO}_{2}{ }^{-}$is not matching with the absorption of rGO even through the successful reduction of GO to rGO utilizing $\mathrm{CO}_{2}{ }^{--}$is well established by steady state electron beam radiolysis. ${ }^{17}$ Again a more complex reaction mechanism should be taken into account. As possible first reaction steps, radical addition (followed by elimination of $\mathrm{CO}_{2}$ ) (eqn (9)), a direct electron transfer (eqn (10)) or a hydrogen carbonate formation (eqn (11)) should be considered. Reaction (eqn (9)) (radical addition) takes into account, that it is well known from inorganic radiation chemistry, that $\mathrm{CO}_{2}{ }^{-}$- reacts preferably in an "inner sphere" electron transfer mechanism ${ }^{39}$ which would favour the proposed addition/elimination mechanism. However, our quantum chemical calculations (see quantum chemical studies Fig. 6) showed that the direct electron transfer (eqn (10)) and the formation of $\mathrm{HCO}_{3}{ }^{-}$(eqn (11)) are the only energetically feasible mechanisms (vide infra) which allow in subsequent follow-up reaction steps forming rGO.

$$
\begin{gathered}
\mathrm{CO}_{2}^{{ }^{-}}+\mathrm{GO} \rightarrow \mathrm{GO}-\left[\mathrm{CO}_{2}{ }^{--}\right] \\
\mathrm{CO}_{2}^{{ }^{-}}+\mathrm{GO} \rightarrow \mathrm{GO}^{--}+\mathrm{CO}_{2} \\
\mathrm{CO}_{2}^{{ }^{-}}+\mathrm{GO} \rightarrow \mathrm{GO}^{\cdot}+\mathrm{HCO}_{3}^{-}
\end{gathered}
$$

In the third approach $\left(\mathrm{CH}_{3}\right)_{2} \mathrm{C}^{\cdot}(\mathrm{OH})$ yet another powerful reductant with a somewhat lower reduction potential $(-1.39 \mathrm{~V}$ vs. NHE) $)^{34}$ compared to $\mathrm{H}^{\cdot}$ and $\mathrm{CO}_{2}{ }^{-}$was investigated.

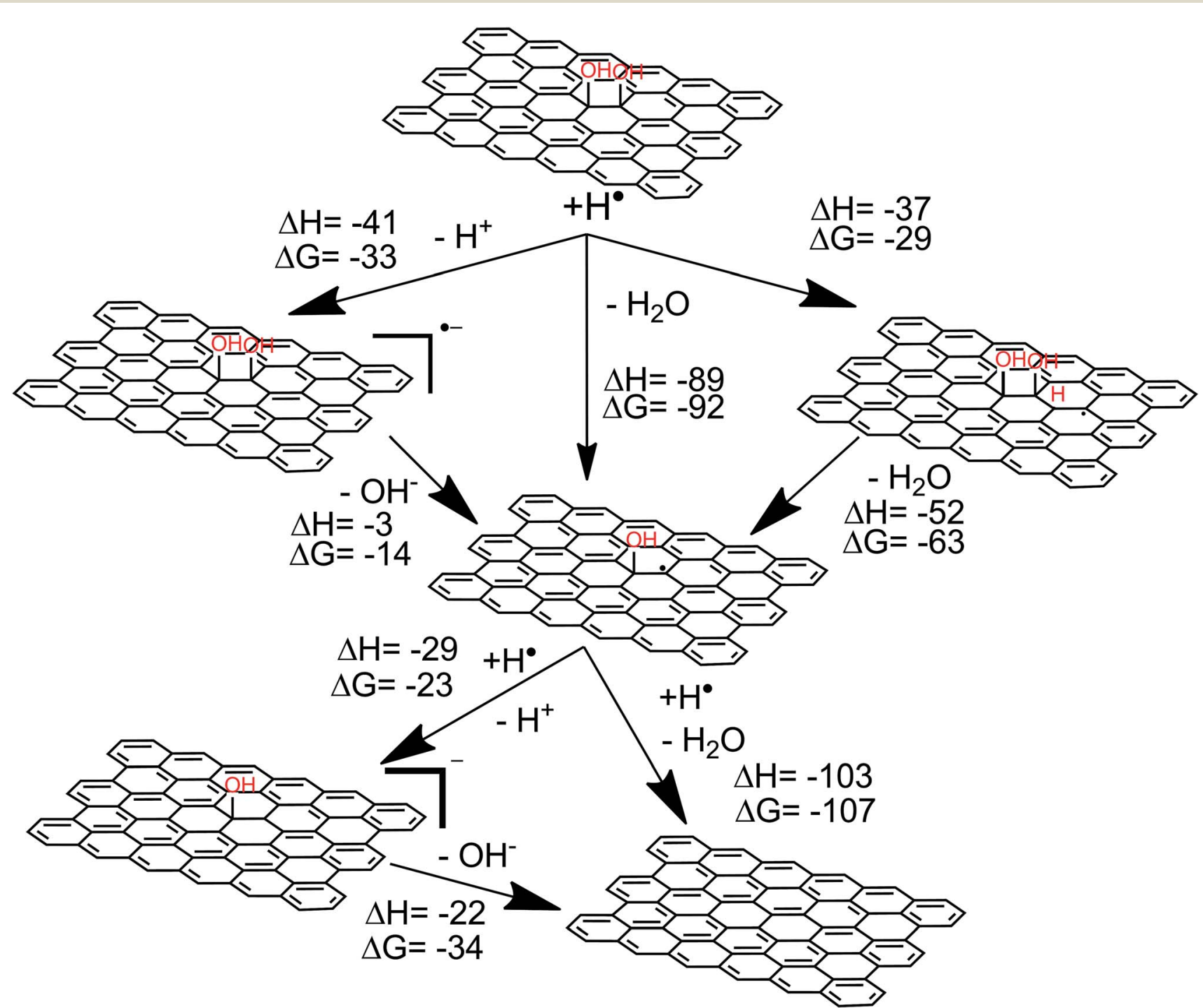

Fig. 5 Reaction scheme of the possible multistep reactions of $H^{*}$ with $\mathrm{GO}$ in water, which lead to the formation of $\mathrm{rGO}(\Delta H-\mathrm{reaction}$ enthalpy $\left(\mathrm{kcal} \mathrm{mol}{ }^{-1}\right), \Delta G-$ Gibbs free energy of reactions $\left(\mathrm{kcal} \mathrm{mol}^{-1}\right)$ ). 
$\left(\mathrm{CH}_{3}\right)_{2} \mathrm{C}^{\cdot}(\mathrm{OH})$ is formed in a standard procedure irradiating $\mathrm{N}_{2} \mathrm{O}$-saturated aqueous solutions containing 5 vol\% 2-propanol. The basic chemistry is similar to the formate-containing system discussed above and is described by eqn (7) and (12). ${ }^{40}$

$$
\cdot \mathrm{OH}\left(\mathrm{H}^{\cdot}\right)+\left(\mathrm{CH}_{3}\right)_{2} \mathrm{CH}(\mathrm{OH}) \rightarrow \mathrm{H}_{2} \mathrm{O}\left(\mathrm{H}_{2}\right)+\left(\mathrm{CH}_{3}\right)_{2} \mathrm{C}^{\cdot}(\mathrm{OH})(12)
$$

In this system an initial transient absorption in the UV region can be addressed to $\left(\mathrm{CH}_{3}\right)_{2} \mathrm{C}^{*}(\mathrm{OH})$ species. It is decaying with an isosbestic point around $410 \mathrm{~nm}$ and gives rise to a broad transient absorption in the visible to NIR regions of the optical spectrum (see Fig. 3 for $\mathbf{0 x o - G _ { 1 }}$ and S5 and S6† for CT-GO and NI-GO).

This kinetics is well fitted to a monoexponential rise. Secondorder rate constants of $5.2 \times 10^{4} \mathrm{ml} \mathrm{mg}^{-1} \mathrm{~s}^{-1}\left(\mathbf{o x o}-\mathbf{G}_{\mathbf{1}}\right) 1.2 \times 10^{5}$ $\mathrm{ml} \mathrm{mg}^{-1} \mathrm{~s}^{-1}$ (CT-GO) and $8.1 \times 10^{4} \mathrm{ml} \mathrm{mg}^{-1} \mathrm{~s}^{-1}$ (NI-GO) were obtained in analogy to the systems described above.

Again, this new transient is not matching with the absorption spectrum of rGO, although the formation of rGO as final product was proved by steady state electron beam or gamma radiolysis, ${ }^{17-20}$ pointing to a multistep reaction mechanism as well.

Here three pathways should be considered: a concerted reaction of $\left(\mathrm{CH}_{3}\right)_{2} \mathrm{C}^{*}(\mathrm{OH})$ with $\mathrm{GO}$ resulting in $\mathrm{GO}^{*}, \mathrm{H}_{2} \mathrm{O}$ and $\left(\mathrm{CH}_{3}\right)_{2} \mathrm{CO}$ (eqn (13)), a radical addition/reductive elimination mechanism and a direct electron transfer with the release of
$\mathrm{OH}^{-}$. From our theoretical calculations (see quantum chemical studies Fig. 7) we conclude, that only the concerted reaction (13) is energetically feasible and leads to rGO.

$$
\left(\mathrm{CH}_{3}\right)_{2} \mathrm{C}^{\cdot}(\mathrm{OH})+\mathrm{GO} \rightarrow \mathrm{GO}^{\bullet}+\left(\mathrm{CH}_{3}\right)_{2} \mathrm{CO}+\mathrm{H}_{2} \mathrm{O}
$$

Finally, $\mathrm{CH}_{3} \mathrm{C}^{*} \mathrm{H}(\mathrm{OH})$ with an even lower reduction potential $(-1.25 \mathrm{~V} v s \text {. NHE })^{34}$ was tested. These species are generated as a major product ( $89 \%$ yield) of the reaction of ${ }^{\circ} \mathrm{OH}$ with ethanol in $\mathrm{N}_{2} \mathrm{O}$-saturated aqueous solution. ${ }^{40}$

Again, the transient absorptions of the primary products of the water radiolysis and subsequently of the formed reducing transient - here $\mathrm{CH}_{3} \mathrm{C}^{*} \mathrm{H}(\mathrm{OH})$ - was observed. The transient absorption of $\mathrm{CH}_{3} \mathrm{C}^{*} \mathrm{H}(\mathrm{OH})$ which essentially dominates the UV region is decaying in GO containing solutions, giving rise to a new transient absorption in the visible and NIR region of the optical spectrum (see Fig. 4). The formation of this transient can be well fitted to a mono-exponential rise and a second-order rate constant of $7.7 \times 10^{4} \mathrm{ml} \mathrm{mg}^{-1} \mathrm{~s}^{-1}$ was received for the reaction of oxo- $\mathbf{G}_{\mathbf{1}}$ with $\mathrm{CH}_{3} \mathrm{C}^{\cdot} \mathrm{H}(\mathrm{OH})$. The transient spectrum with an maximum at $675 \mathrm{~nm}$, observed for the reaction of $\mathrm{CH}_{3} \mathrm{C}^{\cdot} \mathrm{H}(\mathrm{OH})$ with GO does not fit to the absorption of rGO, efficiently formed in steady state electron beam radiolysis. ${ }^{17,18}$

In fact as corroborated by theoretical studies (vide infra) the reduction occurs in a multi-step mechanism. The initial step of the GO reduction by $\mathrm{CH}_{3} \mathrm{C}^{*} \mathrm{H}(\mathrm{OH})$ is an concerted reaction of

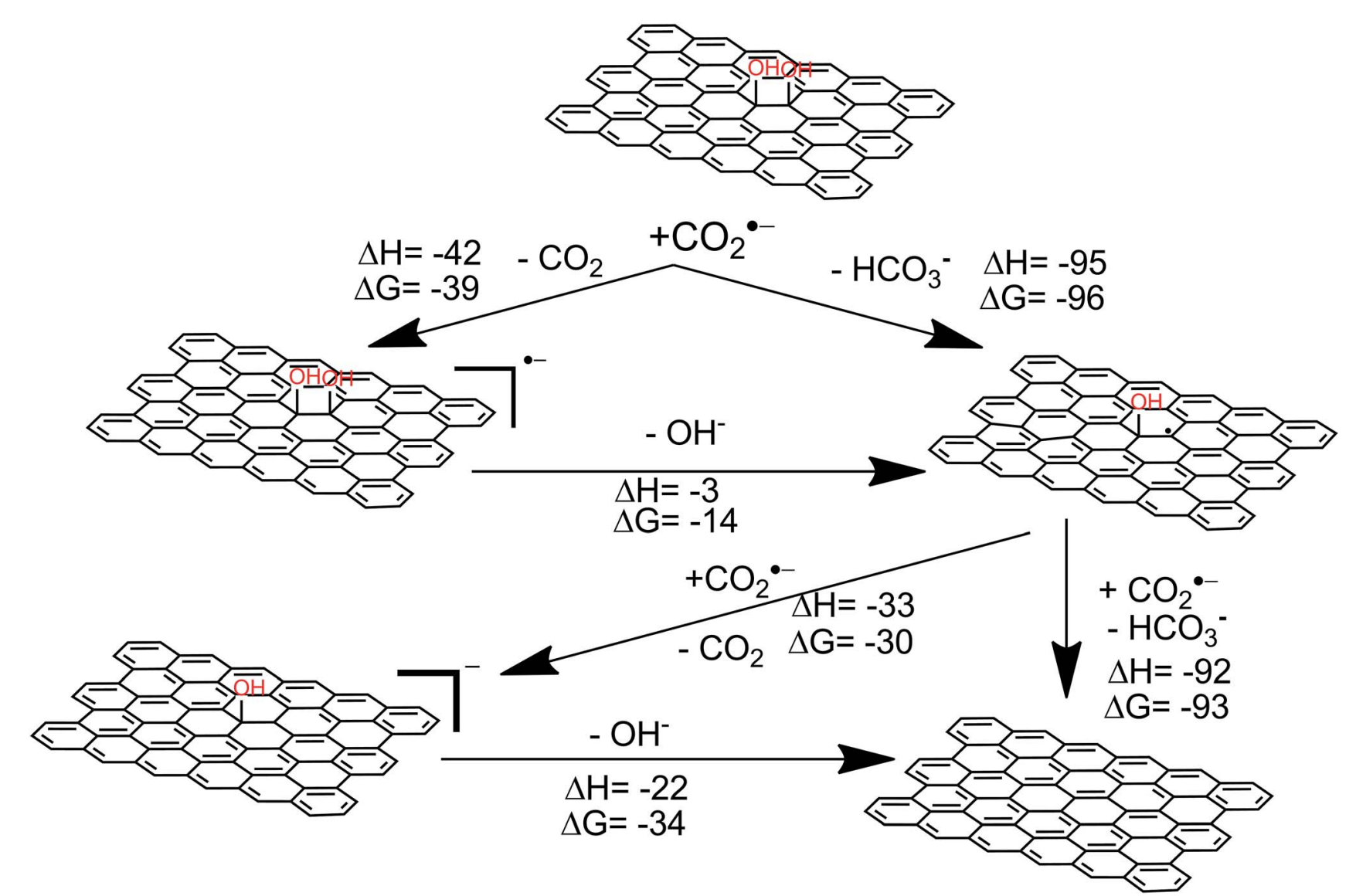

Fig. 6 Reaction scheme of the possible multistep reactions of $\mathrm{CO}_{2} \cdot$ with $\mathrm{GO}$ in water, which lead to the formation of $\mathrm{rGO}(\Delta H-\mathrm{reaction}$ enthalpy (kcal mol$\left.{ }^{-1}\right), \Delta G$ - Gibbs free energy of reactions $\left(\mathrm{kcal} \mathrm{mol}^{-1}\right)$ ). 
the $\mathrm{CH}_{3} \mathrm{C}^{*} \mathrm{H}(\mathrm{OH})$ with GO under the release of water (eqn (14)). The formation of a radical adduct on the basal plane is excluded, since our quantum chemical studies show that this reaction if strongly endergonic.

$$
\mathrm{CH}_{3} \mathrm{C}^{\bullet} \mathrm{H}(\mathrm{OH})+\mathrm{GO} \rightarrow \mathrm{GO}^{\bullet}+\mathrm{H}_{2} \mathrm{O}+\mathrm{CH}_{3} \mathrm{CHO}
$$

From the reducing species studied, the hydrated electrons possess the highest reactivity toward GO. For example, in the reaction with oxo- $\mathbf{G}_{\mathbf{1}}$ its second-order rate constant is 50 times higher than the corresponding one for $\mathrm{H}^{*}$. The latter value is yet more than 20 times higher compared to the reaction of $\mathrm{CO}_{2}{ }^{-}$, resulting in a more than 1000 -fold lower reactivity of the latter species compared to $\mathrm{e}_{\mathrm{aq}}{ }^{-} \cdot{ }^{23}$ This sequence of the reactivities is correlating with reduction potentials of the discussed species changing from $-2.8 \mathrm{~V}$ to $-2.0 \mathrm{~V}$ (see Table 1). However, the reducing radicals derived from 2-propanol and ethanol, with much lower reduction potentials $(-1.4$ and $-1.2 \mathrm{~V})$, do not follow anymore the above mentioned trend.

This is a strong indication for different mechanisms involved. Our quantum-chemical calculations (vide infra) show that for $\mathrm{H}^{\cdot}$ and $\mathrm{CO}_{2}{ }^{--}$electron transfer reactions are a major feasible pathway (see Fig. 5 and 6), whereas $\left(\mathrm{CH}_{3}\right)_{2} \mathrm{C}^{\cdot}(\mathrm{OH})$ and $\mathrm{CH}_{3} \mathrm{C}^{\circ} \mathrm{H}(\mathrm{OH}$ ) react in a concerted reaction releasing water (see Fig. 7 and 8).

It is noteworthy to point out, that only small differences (at most by a factor of $c a$. 2.3, see Table 1) were seen for the rate constants for the reactions of one particular reducing radical with different GO types. Commercial GO (CT-GO/NI-GO) contain around $5-10 \% \mathrm{C}(\mathrm{O}) \mathrm{OH} / \mathrm{COO}^{-}$groups and have a highly defective surface. On the other hand, oxo-G $\mathbf{G}_{\mathbf{1}}$ exhibits an average density of defects of only $0.3 \%$ within the carbon skeleton. ${ }^{13}$ Therefore, we can conclude that the defect density in GO does not play any significant role for the kinetic of its reduction by free radicals.

Summarizing our experiments (Fig. 1-4), it should be pointed out that transient absorptions with three different shapes were observed, namely the transient absorption for the reaction of GO with $\mathrm{H}^{*}, \mathrm{CO}_{2}{ }^{-}$and the $\alpha$-hydroxy-alkyl radicals $\left(\mathrm{CH}_{3} \mathrm{C}^{*} \mathrm{H}(\mathrm{OH})\right.$ and $\left.\left(\mathrm{CH}_{3}\right)_{2} \mathrm{C}^{\cdot}(\mathrm{OH})\right)$. This finding is well in a line with our theoretical studies. These studies predict, depending on the particular reaction partner, three different GO
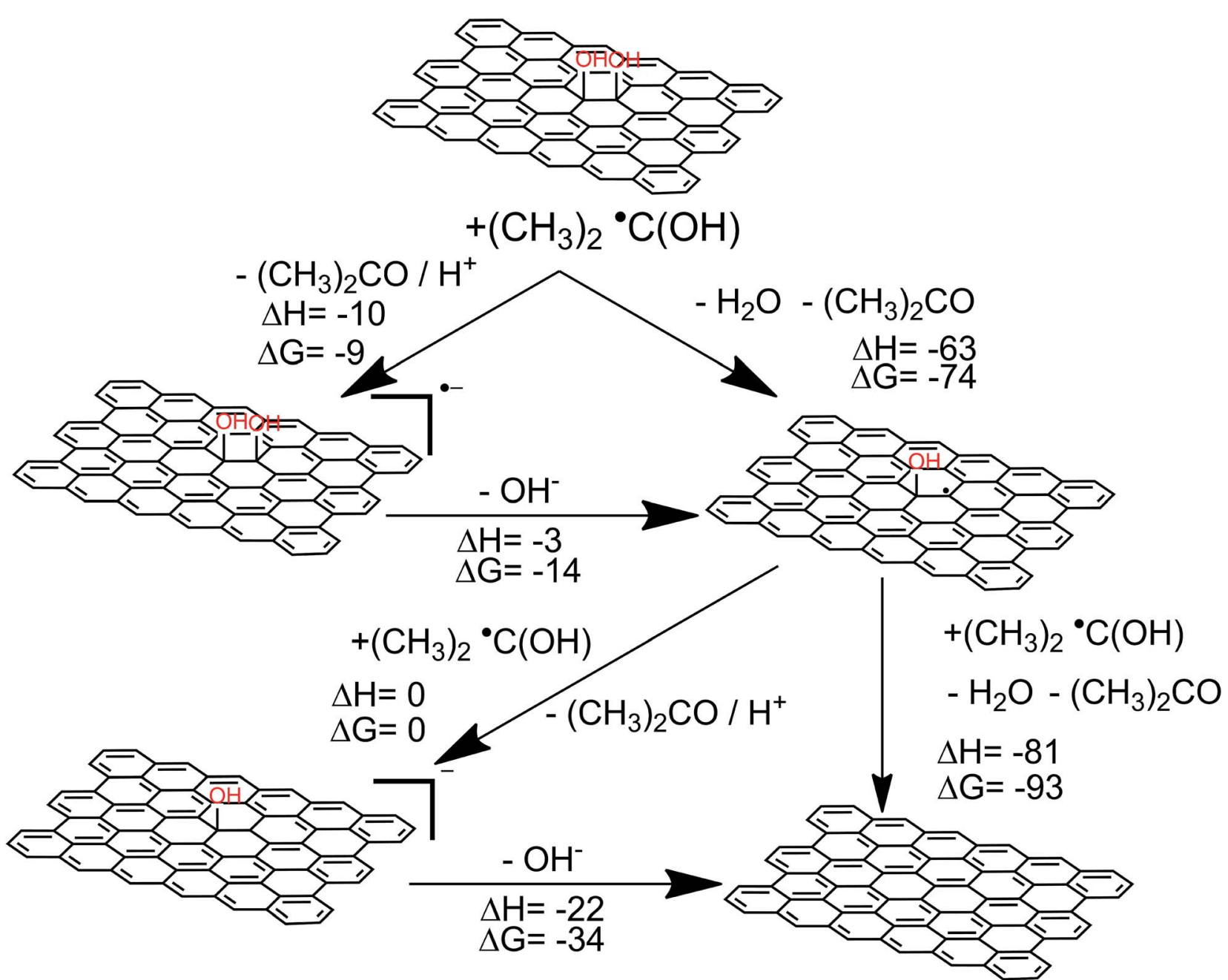

Fig. 7 Reaction scheme of the possible multistep reactions of $\left(\mathrm{CH}_{3}\right)_{2}{ }^{\circ} \mathrm{C}(\mathrm{OH})$ with $\mathrm{GO}$ in water, which lead to the formation of $\mathrm{rGO}(\Delta H-\mathrm{reaction}$ enthalpy (kcal mol$\left.{ }^{-1}\right), \Delta G$ - Gibbs free energy of reactions $\left(\mathrm{kcal} \mathrm{mol}^{-1}\right)$ ). 


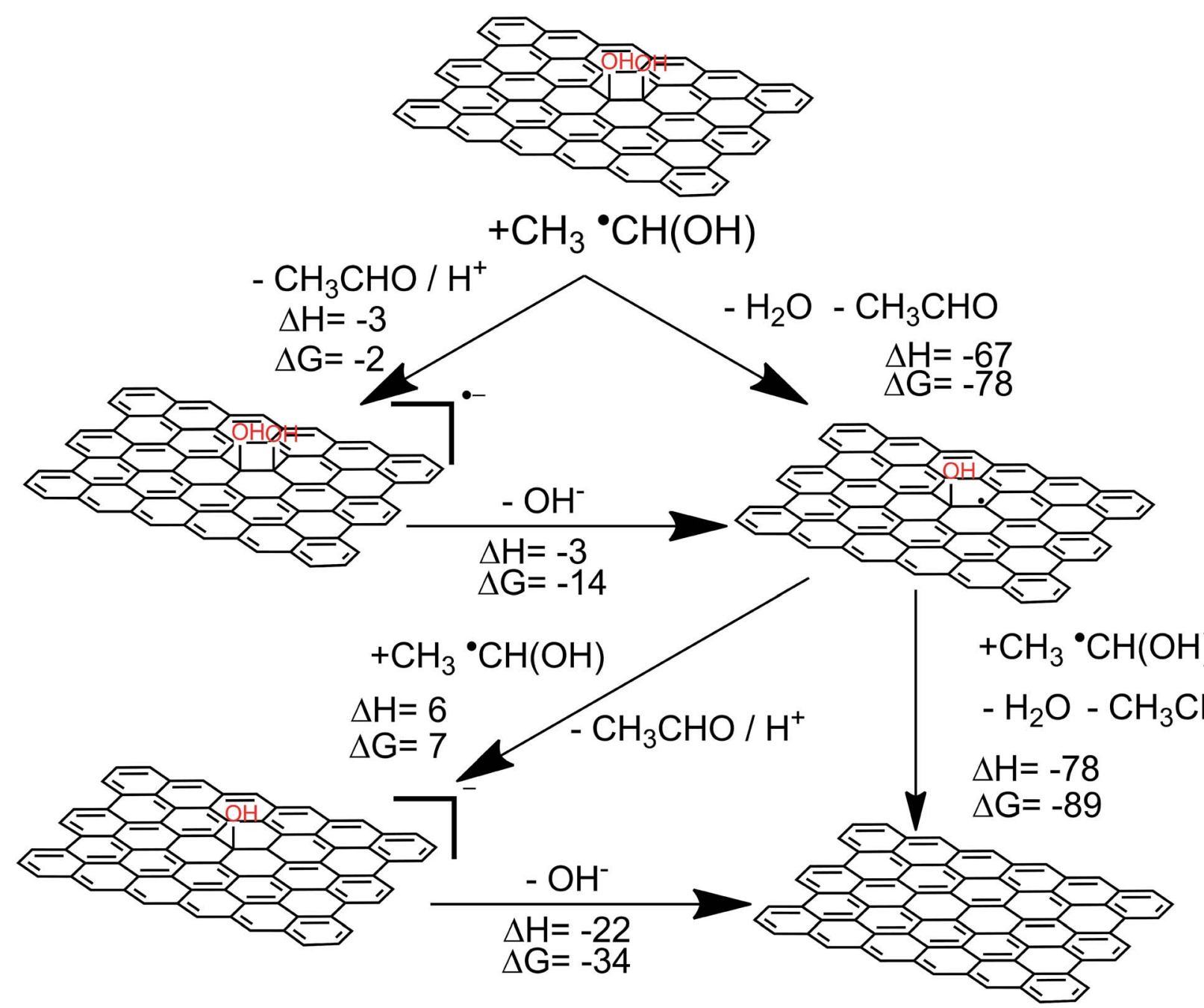

Fig. 8 Reaction scheme of the possible multistep reactions of $\mathrm{CH}_{3} \cdot \mathrm{CH}(\mathrm{OH})$ with $\mathrm{GO}$ in water, which lead to the formation of $\mathrm{rGO}(\Delta H-\mathrm{reaction}$ enthalpy (kcal mol$\left.{ }^{-1}\right), \Delta G-$ Gibbs free energy of reactions $\left(\mathrm{kcal} \mathrm{mol}^{-1}\right)$ ).

intermediates to be formed. In case of the reaction of GO with $\mathrm{H}^{*}$ the parallel formation of all three different intermediates $(\mathrm{GO}-\mathrm{H})^{\circ}, \mathrm{GO}^{\circ}$ and $\mathrm{GO}^{--}$is feasible and the obtained transient absorption is most likely the sum of the transient absorption of all three proposed intermediates. Whereas the reaction of GO with $\mathrm{CO}_{2}{ }^{-}$leads only to the formation of $\mathrm{GO}^{--}$and $\mathrm{GO}^{\circ}$, the reaction of the $\alpha$-hydroxy-alkyl radicals $\left(\mathrm{CH}_{3} \mathrm{C}^{*} \mathrm{H}(\mathrm{OH})\right.$ and $\left.\left(\mathrm{CH}_{3}\right)_{2} \mathrm{C}^{\cdot}(\mathrm{OH})\right)$ leads practically exclusively to the formation of $\mathrm{GO}^{\circ}$. This in regards, depending on the reductive free radical three different intermediates are formed, which lead, nevertheless, to the formation of rGO as final product based on our experimental ${ }^{17,18}$ and theoretical studies (see below).

\section{Quantum chemical calculation}

Possible reaction pathways between studied radicals $\left(\mathrm{H}^{\bullet}, \mathrm{CO}_{2}{ }^{--}\right.$, $\left(\mathrm{CH}_{3}\right)_{2}{ }^{\circ} \mathrm{C}(\mathrm{OH})$ and $\left.\mathrm{CH}_{3}{ }^{\circ} \mathrm{CH}(\mathrm{OH})\right)$ and model $\mathrm{GO}$ with the hexagonal $6 \times 5$ graphene sheet and two $\mathrm{OH}$ groups (shown in Fig. 5-8) were systematically examined. For all radicals three types of reactions were considered: (1) electron transfer (2) radical addition on the GO flake, followed by reductive elimination and (3) a concerted reaction of the reductive free radical with GO. As already known from the pulse radiolysis and electron beam radiolysis measurements the reactions of all investigated free radicals with GO is resulting in the formation of intermediates, which reacts in a multistep mechanism to rGO.

The quantum chemical calculations for the reaction of $\mathrm{H}^{*}$ with GO (Fig. 5) revealed three energetically feasible multi step reaction mechanism (electron transfer, radical addition and a concerted reaction). The formed products are GO` (concerted reaction), $\mathrm{GO}^{--}$(electron transfer) and ${ }^{\circ} \mathrm{GO}-\mathrm{H}$. The latter two $\left(\mathrm{GO}^{-}\right)$and $\left({ }^{\circ} \mathrm{GO}-\mathrm{H}\right)$ react under the release of $\mathrm{OH}^{-}$and $\mathrm{H}_{2} \mathrm{O}$ respectively to $\mathrm{GO}^{\circ}$. In order to obtain $\mathrm{rGO}, \mathrm{GO}^{\bullet}$ necessitates to undergo further transformations, i.e., for our model GO the reaction with a second ${ }^{\circ} \mathrm{H}$. This can occur following two energetically feasible reaction pathways, either by an electron transfer and the subsequent release of $\mathrm{OH}^{-}$or by a concerted reaction with the release of water (Fig. 5).

When turning to $\mathrm{CO}_{2}{ }^{--}$for which the reduction of GO is well established, only the electron transfer from $\mathrm{CO}_{2}{ }^{-}$to the GO 
flake as well as the concerted reaction of $\mathrm{CO}_{2}{ }^{-}-$with the $\mathrm{GO}$ flake under the release of $\mathrm{HCO}_{3}{ }^{-}$is highly exergonic (see Fig. 6). The former reaction (electron transfer) results in $\mathrm{GO}^{-}-$whereas the latter results in $\mathrm{GO}^{\circ}$. $\mathrm{GO}^{\cdot-}$ may react further under $\mathrm{OH}^{-}$ release to $\mathrm{GO}^{\circ}$, for which a reaction with a second $\mathrm{CO}_{2}{ }^{--}$will result in the rGO formation. Here again the $\mathrm{CO}_{2}{ }^{-}$- can react in both ways either via electron transfer forming a $\mathrm{GO}^{-}$which can react under release of $\mathrm{OH}^{-}$to rGO or in a concerted reaction forming $\mathrm{rGO}$ and $\mathrm{HCO}_{3}{ }^{-}$. A radical addition of $\mathrm{CO}_{2}{ }^{-}$onto the GO $\pi$-system was excluded since no stable geometry for such radical adduct was found. When turning to the alpha-hydroxy radicals $\left(\mathrm{CH}_{3}\right)_{2}{ }^{\circ} \mathrm{C}(\mathrm{OH})$ (Fig. 7) and $\mathrm{CH}_{3}{ }^{\circ} \mathrm{CH}(\mathrm{OH})$ (Fig. 8). The energetically most feasible is the concerted reaction of $\left(\mathrm{CH}_{3}\right)_{2}$ ${ }^{\circ} \mathrm{C}(\mathrm{OH})$ and $\mathrm{CH}_{3} \cdot \mathrm{CH}(\mathrm{OH})$ with $\mathrm{GO}$ releasing water. The electron transfer reaction is only slightly exergonic $\left(-9 /-2 \mathrm{kcal} \mathrm{mol}^{-1}\right)$ compared to the concerted reaction which shows a strong driving force $\left(-74 /-78 \mathrm{kcal} \mathrm{mol}^{-1}\right)$ and is therefore much more likely to happen. The reaction results in the formation of GO'. The further reaction of $\mathrm{GO}^{*}$ to rGO can in case of $\left(\mathrm{CH}_{3}\right)_{2}{ }^{\circ} \mathrm{C}(\mathrm{OH})$ and $\mathrm{CH}_{3}{ }^{\circ} \mathrm{CH}(\mathrm{OH})$ only occur in a concerted reaction since the electron transfer reaction lacks of any driving force. A radical addition onto the GO $\pi$-system followed by a reductive elimination was also considered of the reaction of GO with $\left(\mathrm{CH}_{3}\right)_{2}$ ${ }^{\circ} \mathrm{C}(\mathrm{OH})$ and $\mathrm{CH}_{3}{ }^{\circ} \mathrm{CH}(\mathrm{OH})$ but these reactions are highly endergonic and $\Delta \mathrm{G}$ values of $+36\left(\left(\mathrm{CH}_{3}\right)_{2}{ }^{\circ} \mathrm{C}(\mathrm{OH})\right)$ and $+13 \mathrm{kcal}$ $\mathrm{mol}^{-1}\left(\mathrm{CH}_{3}{ }^{\cdot} \mathrm{CH}(\mathrm{OH})\right)$ were obtained, rendering these reactions energetically unfeasible.

Taking the results obtained by the quantum chemical study into concert with the results from the pulse radiolysis the obtained transient absorption of $\mathrm{GO}$ von $\mathrm{H}^{*}$ with it maximum at $520 \mathrm{~nm}$ is most likely the sum of the transient absorption of ${ }^{\circ} \mathrm{GO}-\mathrm{H}, \mathrm{GO}^{\cdot-}$ and $\mathrm{GO}^{\circ}$. All three intermediates are likely to be formed. The transient absorption observed from the reaction of $\mathrm{CO}_{2}{ }^{-}$- with its maximum at $800 \mathrm{~nm}$, is in the light of the quantum chemical calculation best explained as the sum of the transient absorption of $\mathrm{GO}^{\circ-}$ and $\mathrm{GO}^{\circ}$ since both reactions are energetically feasible and likely to happen. The reaction of GO with $\left(\mathrm{CH}_{3}\right)_{2}{ }^{\circ} \mathrm{C}(\mathrm{OH})$ and $\mathrm{CH}_{3}{ }^{\circ} \mathrm{CH}(\mathrm{OH})$ was in both cases showing transient absorption spectra with maxima around $700 \mathrm{~nm}$, which are in line with our quantum chemical calculations in both cases exhibiting $\mathrm{GO}^{\circ}$ as the only energetically feasible intermediate for the $\mathrm{GO}$ reduction.

\section{Conclusions}

Based on the combined pulsed radiolysis and quantumchemical study it was demonstrated that reduction of GO in aqueous dispersions by reducing free radicals proceeds via different mechanisms. They are: radical addition, electrontransfer, concerted water elimination and concerted $\mathrm{HCO}_{3}{ }^{-}$ depending on the selected free radical. All of them are leading finally to rGO, but differ kinetically and by the nature of the intermediates. The latter were characterized for the first time using pulse radiolysis technique. The energetics of the formation and further transformations of GO derived free radical species have been calculated. Our quantum-chemical study helped to distinguish between different possible reduction mechanisms of GO by each particular free radical reductant. It allowed to obtain more insight into the free radical chemistry of $\mathrm{GO}$ in general and into the GO reduction in particular.

Our combined experimental and theoretical approaches corroborated that the rGO formation occurs in a multistep mechanism forming $\mathrm{GO}^{\circ}, \mathrm{GO}^{\circ-}$ and ${ }^{\circ} \mathrm{GO}-\mathrm{H}$ respectively, which react further with the particular reducing radicals to rGO. All observed reaction mechanisms have in common that they reduce GO by the removal of the oxygen functionality from the GO flake but spare the carbon atom. Other simple methods such as thermal treatments or direct photoexcitation also removes the oxygen functionalities by releasing $\mathrm{CO}_{2}$ and $\mathrm{CO}$. However it is not leading to a substantial repair of the carbon $\pi$ system. ${ }^{41}$

In contrary the indirect reduction using reducing free radicals is avoiding the loss of the carbon atoms from the carbon framework and, moreover, recreating the carbon $\pi$-system - in other words the graphene oxide becomes repaired towards graphene. This repair can be simply followed by conductivity measurements accompanied by XPS measurements where values of $5500 \mathrm{~S} \mathrm{~m}^{-1}$ and $\mathrm{C} / \mathrm{O}$-atom rations up to 10.9 were obtained for the reduction of oxo- $\mathbf{G}_{1}$ by $\left(\mathrm{CH}_{3}\right)_{2}{ }^{\circ} \mathrm{C}(\mathrm{OH}) \cdot{ }^{22}$ Even for commercial CT-GO, which bears large holes in the GO basal plain, conductivity values of $500 \mathrm{~S} \mathrm{~m}^{-1}$ were observed. ${ }^{22}$

\section{Acknowledgements}

AK, BA and SE gratefully acknowledge funding from the Deutsche Forschungsgemeinschaft (DFG) via Grant KA 3491/2-1, AB 63/14-1, EI 938/3-1. RF, WK and BA acknowledge funding from the Bundesministerium für Bildung und Forschung via Project "Nanotrace" (BMBF-03X0130).

\section{Notes and references}

1 K. S. Novoselov, A. K. Geim, S. V. Morozov, D. Jiang, Y. Zhang, S. V. Dubonos, I. V. Grigorieva and A. A. Firsov, Science, 2004, 306, 666.

2 A. K. Geim and K. S. Novoselov, Nat. Mater., 2007, 6, 183.

3 D. C. Elias, R. R. Nair, T. M. G. Mohiuddin, S. V. Morozov, P. Blake, M. P. Halsall, A. C. Ferrari, D. W. Boukhvalov, M. I. Katsnelson, A. K. Geim and K. S. Novoselov, Science, 2009, 323, 610.

4 M. J. Allen, V. C. Tung and R. B. Kaner, Chem. Rev., 2010, 110, 132.

5 L. Vicarelli, S. J. Heerema, C. Dekker and H. W. Zandbergen, ACS Nano, 2015, 9, 3428.

6 W. Yuan and G. Shi, J. Mater. Chem. A, 2013, 1, 10078.

7 F. Schedin, A. K. Geim, S. V. Morozov, E. W. Hill, P. Blake, M. I. Katsnelson and K. S. Novoselov, Nat. Mater., 2007, 6, 652.

8 F. Bonaccorso, L. Colombo, G. Yu, M. Stoller, V. Tozzini, A. C. Ferrari, R. S. Ruoff and V. Pellegrini, Science, 2016, 347, 1246501.

9 K. S. Balasingam and Y. Jun, Isr. J. Chem., 2015, 55, 955.

10 A. Ambrosi, C. K. Chua, A. Bonanni and M. Pumera, Chem. Rev., 2014, 114, 7150 and references herein. 
11 J. Zhu, D. Yang, Z. Yin, Q. Yan and H. Zhang, Small, 2014, 10, 3480 and references herein.

12 A. Ciesielski and P. Samori, Chem. Soc. Rev., 2014, 43, 381.

13 S. Eigler and A. Hirsch, Angew. Chem., Int. Ed., 2014, 53, 7720 and references herein.

14 C. K. Chua and M. Pumera, Chem. Soc. Rev., 2014, 43, 291 and references herein.

15 S. Eigler, C. Dotzer and A. Hirsch, Carbon, 2012, 50, 3666.

16 S. Eigler, Chem.-Eur. J., 2016, 22, 7012 and references herein.

17 R. Flyunt, W. Knolle, A. Kahnt, A. Prager, A. Lotnyk, J. Malig, D. M. Guldi and B. Abel, Int. J. Radiat. Biol., 2014, 90, 486.

18 R. Flyunt, W. Knolle, A. Kahnt, S. Eigler, A. Lotnyk, T. Häupl, A. Prager, D. M. Guldi and B. Abel, Am. J. Nano Res. Appl., 2014, $2,9$.

19 J.-M. Jung, C.-H. Jung, M.-S. Oh, I.-T. Hwang, C.-H. Jung, K. Shin, J. Hwang, S.-H. Park and J.-H. Choi, Mater. Lett., 2014, 126, 151.

20 Y. Zhang, H.-L. Ma, Q. Zhang, J. Peng, J. Li, M. Zhai and Z.-Z. Yu, J. Mater. Chem., 2012, 22, 13064.

21 A. Kahnt, R. Flyunt, C. Laube, W. Knolle, S. Eigler, R. Hermann, S. Naumov and B. Abel, Nanoscale, 2015, 7, 19432.

22 R. Flyunt, W. Knolle, A. Kahnt, C. E. Halbig, A. Lotnyk, T. Häupl, A. Prager, S. Eigler and B. Abel, Nanoscale, 2016, 8, 7572 .

23 S. Eigler, Phys. Chem. Chem. Phys., 2014, 16, 19832.

24 S. Eigler, M. Enzelberger-Heim, S. Grimm, P. Hofmann, W. Kroener, A. Geworski, C. Dotzer, M. Röckert, J. Xiao, C. Papp, O. Lytken, H.-P. Steinrück, P. Müller and A. Hirsch, Adv. Mater., 2013, 25, 3583.

25 E. M. Fielden, Chemical Dosimetry of Pulsed Electron and XRay Sources in the 1-20 MeV Range, in The Study of Fast Processes and Transient Species by Electron Pulse Radiolysis, ed. J. H. Baxendale and F. Busi, NATO, Advances Study Institutes Series C. Mathematical and Physical Sciences, 1982, p. 86.

26 M. R. Ganapathi, R. Hermann, S. Naumov and O. Brede, Phys. Chem. Chem. Phys., 2000, 2, 4947.

27 A. D. Becke, J. Chem. Phys., 1996, 104, 1040.

28 C. Lee, W. Yang and R. G. Parr, Phys. Rev. B: Condens. Matter Mater. Phys., 1988, 37, 785.

29 Jaguar, Version 8.3, Schrodinger, Inc., New York, NY, 2014.

30 D. J. Tannor, B. Marten, R. Murphy, R. A. Friesner, D. Sitkoff, A. Nicholls, M. Ringnalda, W. A. Goddard III and B. Honig, J. Am. Chem. Soc., 1994, 116, 11875.

31 S. Horn, F. Plasser, T. Müller, F. Libisch, J. Burgdörfer and H. A. Lischka, Theor. Chem. Acc., 2014, 133, 1511.

32 S. Rayne and K. Forest, Comput. Theor. Chem., 2011, 977, 163. 33 K. P. Madden and S. P. Mezyk, J. Phys. Chem. Ref. Data, 2011, 40, 023103.

34 P. Wardman, J. Phys. Chem. Ref. Data, 1989, 18, 1637.

35 S. O. Nielsen, B. D. Michael and E. J. Hart, J. Phys. Chem., 1976, 80, 248.

36 H. Christensen and K. Sehested, J. Phys. Chem., 1983, 87, 118.

37 G. V. Buxton, C. L. Greenstock, W. P. Helman and A. B. Ross, J. Phys. Chem. Ref. Data, 1988, 17, 513.

38 P. Neta, M. Simic and E. Hayon, J. Phys. Chem., 1969, 73, 4207.

39 I. Zilbermann, E. Maimon, H. Cohen and D. Meyerstein, Chem. Rev., 2005, 105, 2609.

40 K.-D. Asmus, H. Möckel and A. Henglein, J. Phys. Chem., 1973, 77, 1218.

41 R. Trusovas, K. Ratautas, G. Raciukaitis, J. Barkauskas, I. Stankeviciene, G. Niaura and R. Mazeikiene, Carbon, 2013, 52, 574 . 